\title{
CONTRIBUTO PARA O ESTUDO DOS CONTEXTOS FUNERÁRIOS DO NOROESTE PORTUGUÊS: O CASO DE ESTUDO DA QUINTA DO AMORIM 2, BRAGA
}

\author{
Hugo Aluai SAmpaio $^{(1)}$, Maria Jõ̃o Amorim $^{(2)}$, Luciano Vilas Boas ${ }^{(3)} \&$ Ana CATARina G. Braga ${ }^{(4)}$
}

Resumo:

Abstract:

\begin{abstract}
Este trabalho pretende dar a conhecer parte dos dados resultantes da escavação arqueológica do sítio da Quinta do Amorim 2, freguesia de S. Victor, concelho e distrito de Braga, Noroeste de Portugal. Durante os trabalhos de acompanhamento arqueológico da construção do Novo Hospital de Braga (NHB), o achado de um perfil de um vaso quase exclusivo de contextos funerários (largo bordo horizontal forma 13c de Bettencourt, 1999) e de um fragmento de outro vaso de tipologia semelhante, posteriormente seguido da identificação de uma sepultura plana, durante os trabalhos de escavação impostos pela tutela, confirmam a importância do local no âmbito das práticas funerárias da Idade do Bronze. A estrutura escavada incluía uma terceira forma $13 \mathrm{c}$, recolhida em contexto primário, cujas aderências orgânicas permitiram uma datação radiométrica

Recorrendo a analogias com contextos coetâneos onde surge este tipo de indício (ALMEIDA \& FERNANDES 2007, 2008; ALMEIDA et al. 2008; SAMPAIO et al. 2008; BETTENCOURT 2010) equaciona-se a hipótese de estarmos perante uma necrópole da Idade do Bronze Médio que combinou a tumulação de indivíduos com a deposição de materiais cerâmicos.
\end{abstract}

Palavras-chave: Noroeste português, Bronze Médio, necrópole, sepultura plana, deposições cerâmicas.

Contribution for the study of the Bronze Age funerary contexts in the Portuguese Northwest: the case study of Quinta do Amorim 2, Braga

This work aims to present part of the data recovered at the archaeological excavation at Quinta do Amorim 2, parish of S. Victor, county and district of Braga, Northwest of Portugal.

The discovery of a ceramic flat edge vessel profile - form 13c from the table of forms of Bettencourt (1999) -, an almost specific funerary context form, and a fragment of a third similar vase, in the archaeological monitoring of the Braga's New Hospital $(\mathrm{BNH})$, later followed by the identification of a plain grave, during the excavation of the site imposed by the Portuguese archaeological custody, confirm the importance of this place regarding to the Bronze Age funerary practices. Nevertheless, the excavated structure included a third form $13 \mathrm{c}$ vessel, recovered in primary context, which its organic adherences have allowed a radiometric date.

Using similar and coetaneous contexts where these kinds of evidence have appeared (ALMEIDA \& FERNANDES 2007, 2008; ALMEIDA et al. 2008; SAMPAIO et al. 2008; BETTENCOURT 2010), it is hypothesized an use of this area compatible with a Middle Bronze Age necropolis, which has combined the burial of people and the deposition of ceramic materials.

Keywords: Northwest of Portugal; Middle Bronze Age, necropolis, plain grave, ceramic depositions.

Received: 19 November 2013; Accepted: 24 January, 2014

"It is easy to explain the (...) choice of location by reference to a single activity (a good place to hunt) or outlook (a good viewpoint), but the place may have been valued for a combination of reasons, including its cumulative oldness."

Alasdair Whittle (2010: 41)

\section{INTRODUÇÃ̃}

Foi durante o acompanhamento arqueológico da construção do Novo Hospital de Braga (NHB), concretamente, enquanto se procedia à abertura mecânica de uma vala com cerca de 1,5 metros de profundidade para a colocação de tubagens, que Vilas Boas recolheu alguns fragmentos cerâmicos cujas caraterísticas técnicas e formais se enquadravam na Idade do Bronze.

Alertado o então Instituto de Gestão do Património Arquitectónico e Arqueológico, IP, foram impostos trabalhos de escavação arqueológica que salvaguardassem quaisquer vestígios identificados na área afeta à obra.

\footnotetext{
(1) Arqueólogo, doutorando em Arqueologia da Paisagem e do Povoamento na Universidade do Minho, Braga, bolseiro de doutoramento pela Fundação para a Ciência e Tecnologia (SFRH/BD/41776/2007) e investigador do Centro de Investigação Transdisciplinar Cultura, Espaço e Memória (CITCEM/UM). Email: hugoaluai@gmail.com.

(2) Arqueóloga. Mestranda em Arqueologia na Universidade do Minho, Braga e investigadora do Centro de Investigação Transdisciplinar Cultura, Espaço e Memória (CITCEM/UM). Email: marijoo.amorim@gmail.com.

3) Arqueólogo. Mestrando em Arqueologia na Universidade do Minho, Braga e investigador do Centro de Investigação Transdisciplinar Cultura, Espaço e Memória (CITCEM/UM).Email: lucianomvb@gmail.com.

(4) Memória (CITCEM/UM). Email: lucianomvb@gmail.com.
} 
Os trabalhos de escavação dos vestígios maioritariamente da Idade do Bronze ${ }^{1}$ foram coordenados por dois signatários deste texto (HAS e MJA). O terreno a intervir foi dividido em duas áreas. A Área 1 foi implementada a norte do antigo campo de futebol $O S$ Alegrienses, entre as linhas altimétricas dos 280 e 290 metros, numa pendente suave a sul do marco trigonométrico de Pedroso. A Área 2 ocupou o terreno a este daquele recinto desportivo, uma pendente suave que se desenvolvia para poente a partir de uma pequena plataforma que se destacava a cerca de $1 \mathrm{~km}$ para sul do monte de Pedroso. Aqui os vestígios dispersavam-se entre os 270 e os 280 metros de altitude.

Em ambos os espaços apareceram estruturas em negativo no substrato rochoso, na maioria dos casos associadas a escassos materiais cerâmicos, por vezes incluindo, também, fragmentos de moinhos manuais (dormentes e moventes). É com base numa estrutura específica identificada e escavada na Área 2 (estrutura 12), que incluía o depósito de um vaso no seu interior, bem como no que resta de alguns recipientes cerâmicos recolhidos nas suas imediações e estudados por um de nós (ACGB), que se considera a hipótese de aqui ter sido construída, durante a Idade do Bronze, uma necrópole.

Com base nestas materialidades, pretende-se aumentar o conhecimento sobre o universo funerário das comunidades da Idade do Bronze. Este exercício implicou a utilização de duas escalas de análise distintas, ao nível do micro-contexto (analisando a estrutura funerária) e ao nível do intrassítio ${ }^{2}$.

Num primeiro momento foram observados os fragmentos cerâmicos recolhidos durante $\mathrm{o}$ acompanhamento arqueológico (provenientes da abertura da vala) que aparentavam relações com práticas funerárias. Tal tarefa atendeu às suas caraterísticas técnicas e formais.

Posteriormente foram analisadas a forma, as dimensões e algumas caraterísticas particulares registadas durante os trabalhos de campo da estrutura 12. Os materiais do seu enchimento foram igualmente observados sob os mesmos critérios dos restantes.

A datação radiométrica deste contexto suporta a cronologia proposta e os paralelos com contextos coetâneos do Noroeste peninsular servem para corroborar as interpretações apresentadas.

\section{LOCALIZAÇÃO ADMINISTRATIVA, ENQUADRAMENTO FÍSICO E AMBIENTAL E CONTEXTO ARQUEOLÓGICO}

O sítio da Quinta do Amorim 2 localiza-se na freguesia de S. Victor, no concelho e distrito de Braga, concretamente, a poente da rua José Ferreira Alves. Segundo o Sistema WGS 84, às coordenadas geográficas de $41,566240 \mathrm{~N}$ e $-8,397245 \mathrm{~W}$, variando a altitude do local entre os 260 e os 270 metros (Fig. 1).

O local do achado, destacando-se nos contrafortes

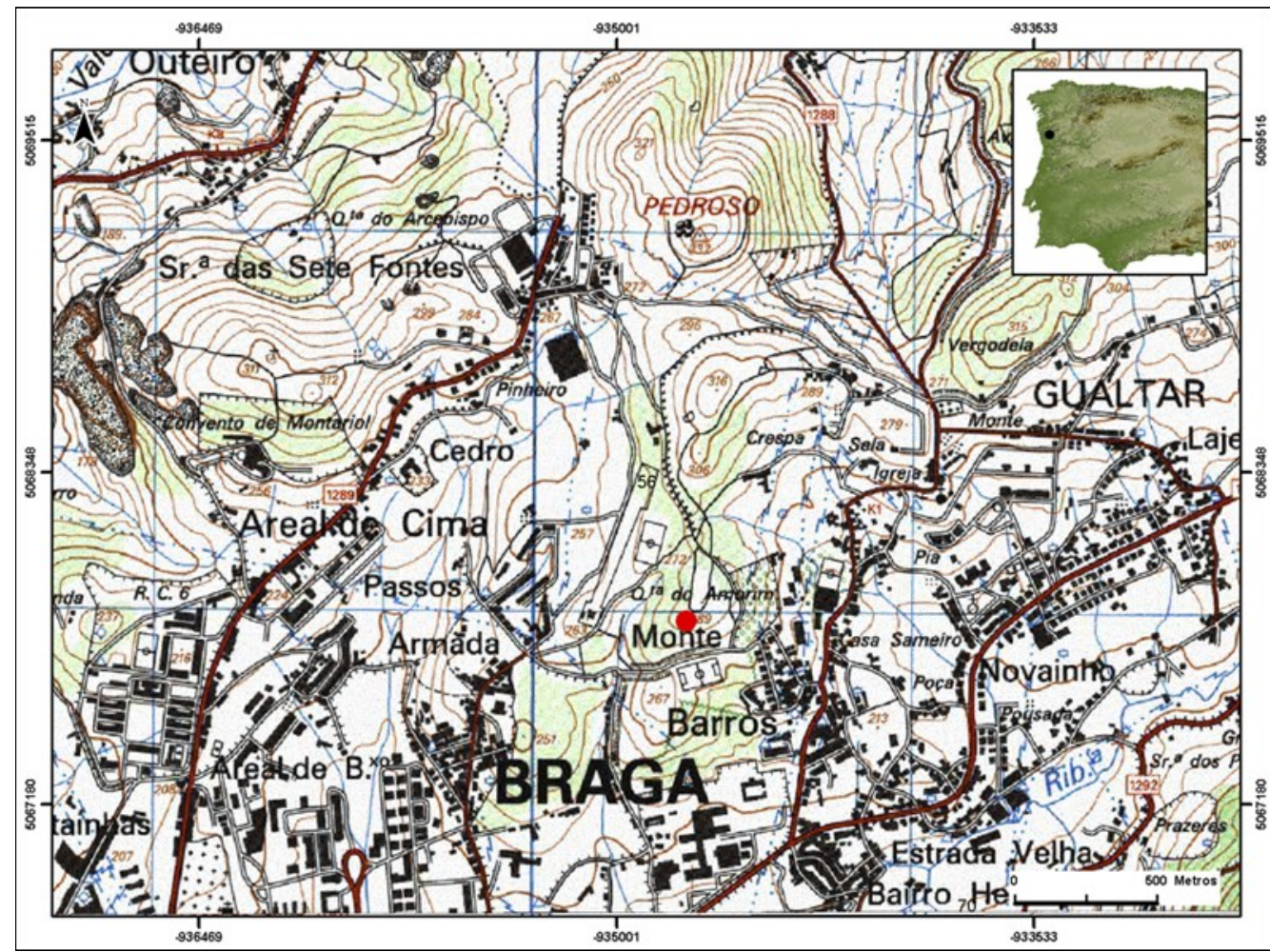

Fig. 1. Excerto de Carta Militar de Portugal, folha 56, à escala 1/25 000, sobre Modelo Digital de Terreno com localização do sítio da Quinta do Amorim II.

Fig. 1. Excerpt of Portuguese Military Map, sheet 56, at scale 1/25 000, over Digital Terrain Modelling with the location of Quinta do Amorim.

Maioritariamente porque, nas imediações, foram sendo identificadas outras estruturas em negativo de época histórica.

Note-se que apenas foram consideradas as materialidades entendidas como diretamente relacionadas com as práticas funerárias. 
sudoeste da Serra do Carvalho, ocupa uma plataforma a meio da vertente sul do monte de Pedroso, distando menos de $1 \mathrm{~km}$ do marco trigonométrico que ali marca o ponto mais elevado (Figs. $1 \mathrm{e} 2$ ).

O local está próximo da cumeada que separa as bacias hidrográficas do rios Cávado, a norte, e Ave, a sul, integrando esta última. Além disso, é sobranceiro ao interflúvio da ribeira de Areal e da ribeira de Gualtar, afluentes do rio Este pela sua margem direita, ambos tributários do rio Ave. A sua proximidade, de cerca de 500 metros para oeste e sudoeste, respetivamente, de ambas as ribeiras, permite-lhe boa visibilidade para os vales de aptidão agrícola.

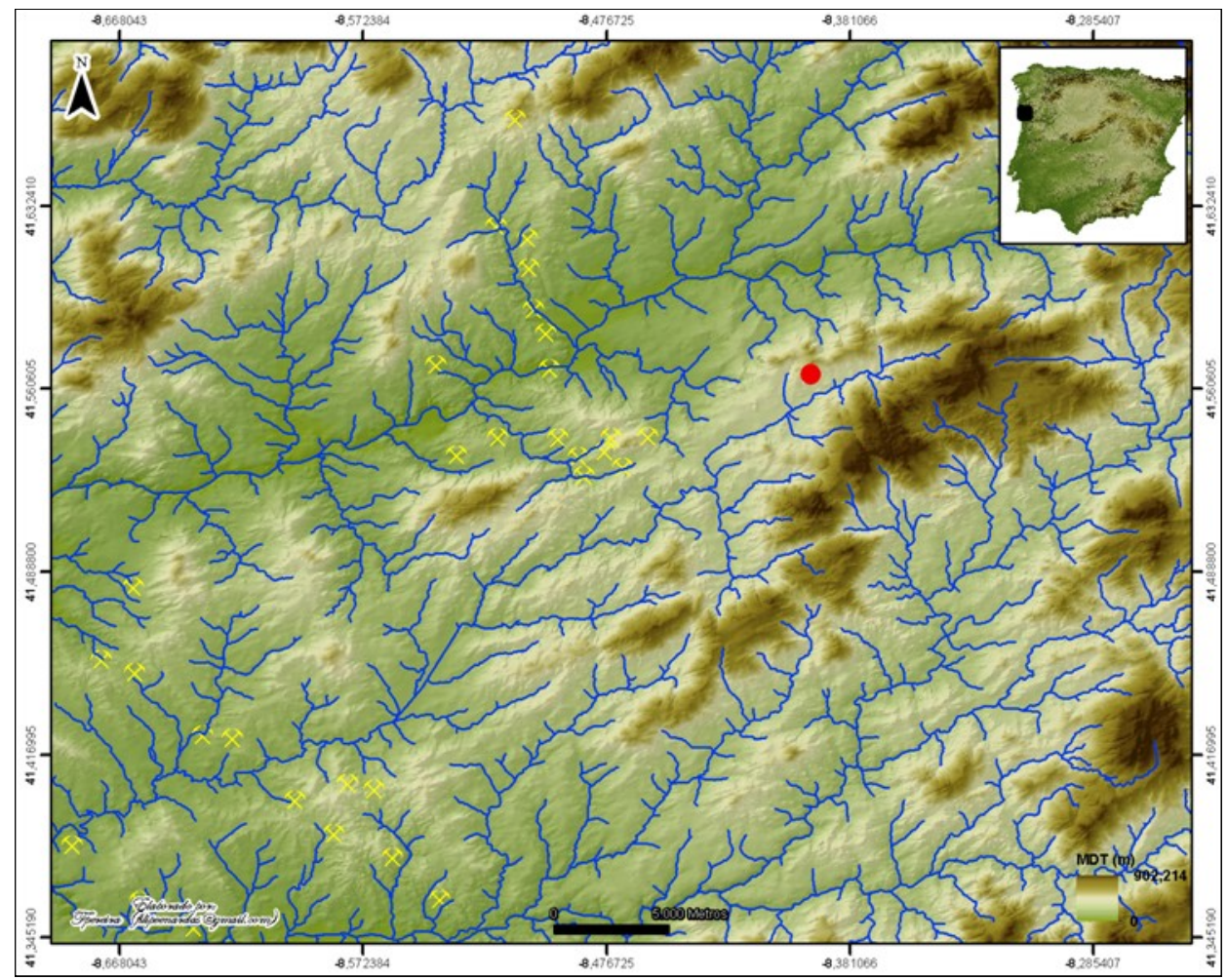

Fig. 2. Mapa hipsométrico 3D com localização da Quinta do Amorim II face aos cursos de águas e às jazidas mineiras de estanho.

Fig. 2. 3D Hypsometric map with Quinta do Amorim's location in relation to the surrounding water courses and tin ores.

A água detém papel preponderante na área, conforme se atesta pelo sistema de abastecimento de água das Sete Fontes, construído em época moderna, como pela boa capacidade de drenagem dos terrenos, permitindo que nos vales circundantes se formem solos de aproveitamento agrícola.

Pela análise da Carta Geológica de Portugal (C.G.P.), folha 5-D de Braga, à escala 1/50 000 (FERREIRA et al. 2000), verifica-se que o local ocupa a extremidade noroeste de uma faixa de granodiorito que se desenvolve desde Longos/ Briteiros, Guimarães, naquele sentido. Nela se incluem monzogranitos biotíticos, porfiroides, de grão médio, orientado, com presença de megacristais de feldspato potássico (também denominado de Granito do Sameiro). Segundo L. Gonçalves $^{3}$ (comunicação pessoal), sobretudo no quadrante noroeste da área intervencionada afloram pontualmente monzogranitos biotíticos, com rara moscovite, tendencialmente porfiróides, de grão médio a fino (Granito de Braga). Muito próximo encontra-se uma zona de contacto com metassedimentos paleozóicos, formada por xistos e micaxistos, que integram a Unidade de Vila Nune.

Observando as C.G.P., à escala 1/50 000, folhas 5-C de Barcelos (TEIXEIRA \& MEDEIROS 1969), 5-D de Braga (FERREIRA et al. 2000) e 9-A de Póvoa de Varzim (TeIXeIRA et al. 1965), verifica-se a presença de recursos mineiros a cerca de $10 \mathrm{~km}$ para poente, no complexo de jazidas de estanho de Cabreiros/Padim da Graça, Braga, a pouco mais de $15 \mathrm{~km}$ para noroeste, no complexo de jazidas de estanho de Parada de Gatim/ Cabanelas, Vila Verde, e a cerca de $18 \mathrm{~km}$ para noroeste, nas mineralizações auríferas de Portela das Cabras, Vila Verde. Minerais de aluvião estariam igualmente disponíveis num raio de cerca de $15 \mathrm{~km}$, concretamente, nas margens dos rios

3 Geólogo do Departamento de Ciências da Terra da Universidade do Minho 
Cávado, a nor-noroeste, e dos rios Este e Ave, a susudoeste.

Atualmente a área é coberta essencialmente por espécies arbustivas esparsamente pontuadas por algumas árvores, entre os quais sobressaem os carvalhos.

No que respeita a vestígios arqueológicos, e restringindo o presente trabalho ao período cronológico-cultural em questão (Bronze), está identificado a cerca de 200 metros para nascente um possível povoado de fossas denominado de Caixa d'Água, Bouça do Monte ou Quinta do Amorim (BARBosA \& AZEVEDo 2003-2004). Os seus vestígios distribuem-se pelo topo e vertente sul de um patamar que atinge os 288 metros de altitude e que se destaca na vertente sul do monte de Pedroso. Parece claro que a presença destes vestígios potenciava a presença de outros nas imediações, facto que com a construção do NHB se veio a comprovar. Infelizmente, a área tem visto a recorrente construção de moradias sem o devido acautelamento de quaisquer trabalhos de acompanhamento arqueológico, apesar dos terrenos estarem condicionados no Plano Diretor Municipal de Braga.

\section{OS DADOS}

Entre os materiais cerâmicos recolhidos nas terras provenientes da abertura mecânica da vala na Área 2 e que, de resto, estão na origem dos trabalhos de escavação, figuram restos de três vasos de bordo horizontal ou forma $13 \mathrm{c}$ da tabela formal de Bettencourt (1999). Duas dessas formas fazem-se representar por partes do bordo, correspondendo a terceira a um perfil completo 4 .

De um modo geral estes materiais revelam fabrico manual, pastas arenosas, texturas grosserias e cozeduras redutoras de boa qualidade. Os seus acabamentos incluem polimento externo e alisamento interno, que lhes confere um toque gorduroso típico dos materiais deste período. Incluem, ainda, vestígios de fuligem em ambas as faces. No interior da aba dos seus bordos foi possível identificar a presença de decorações metopadas efetuada com recurso à técnica de incisão ou combinando incisão com impressão. O perfil completo (2011.0252) revela incisões efetuadas com objeto de ponta romba, formando segmentos de linha de espessura e comprimento variáveis dispostos em posições oblíquas ao lábio (Fig. 3).

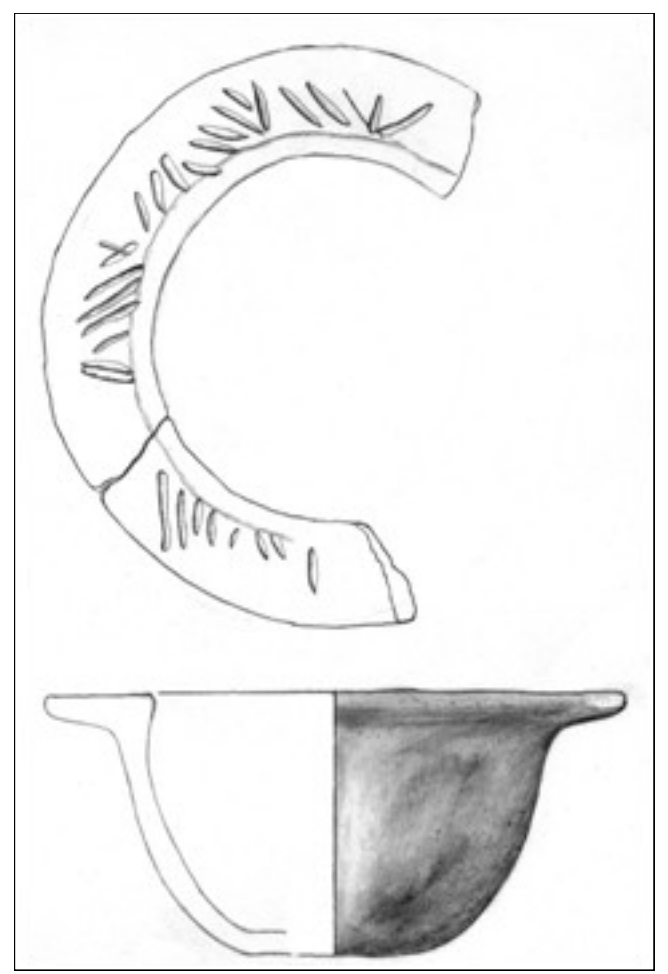

Fig. 3. Perfil de vaso cerâmico com o $\mathrm{n}^{\circ}$ de inventário 2011.0252.

Fig. 3. Ceramic vessel profile with the inventory number 2011.0252 .

Um dos fragmentos (2011.0253) conjuga pequenas linhas incisas, também de espessura e de comprimento variáveis, com impressões de motivos subretanglares dispostos no sentido transversal ao bordo, separando as linhas incisas e formando métopas (Fig. 4).

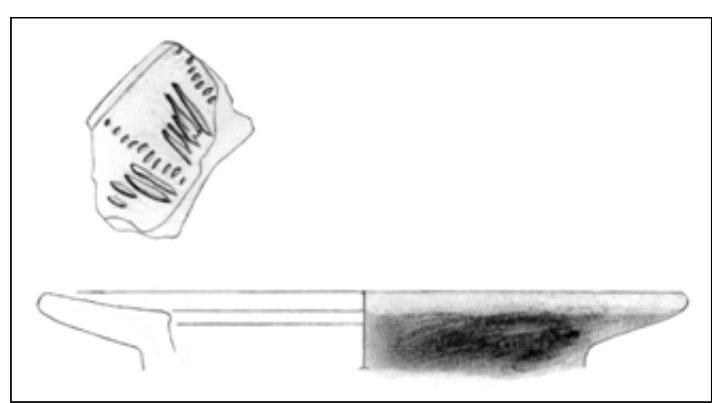

Fig. 4. Fragmento cerâmico com o $\mathrm{n}^{\mathrm{o}}$ de inventário 2011.0253.

Fig. 4. Ceramic fragment with the inventory number 2011.0253

O outro fragmento (2011.1491) inclui a representação de duas linhas paralelas ao lábio que se formam por sucessivas impressões de motivos sublosangulares.

4 Em depósito no Museu Regional de Arqueologia D. Diogo de Sousa, em Braga. 
Uma delas localiza-se diretamente sobre o lábio e a outra na extremidade exterior da aba. Nesta surgem, também, incisões de segmentos de linha, elaborados com artefacto de ponta romba, dispostos em sentido oblíquo ao lábio e variando de direção, quer para a esquerda quer para a direita (Fig. 5).

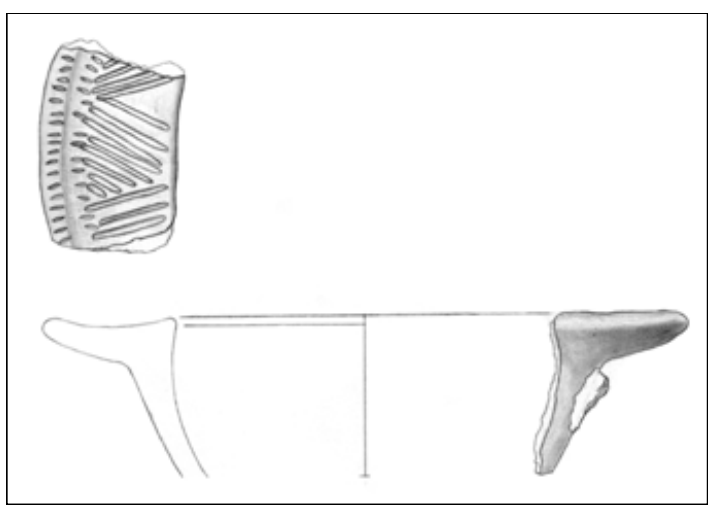

Fig. 5. Fragmento cerâmico com o $\mathrm{n}^{\mathrm{o}}$ de inventário 2011.1491 e respetivo perfil.

Fig. 5. Ceramic fragment with the inventory number 2011.1491 and its profile.

Já durante os trabalhos de escavação a equipa identificou uma estrutura (estrutura 12) que havia sido cortada transversalmente pela vala aberta mecanicamente. Tal foi conseguido através da observação do perfil da referida vala onde era visível, de ambos os lados, o enchimento de uma secção em "U", com cerca de $15 \mathrm{~cm}$ de profundidade, com um sedimento de coloração castanho-escuro. Posteriormente esta estrutura foi definida em plano (Fig. 6).

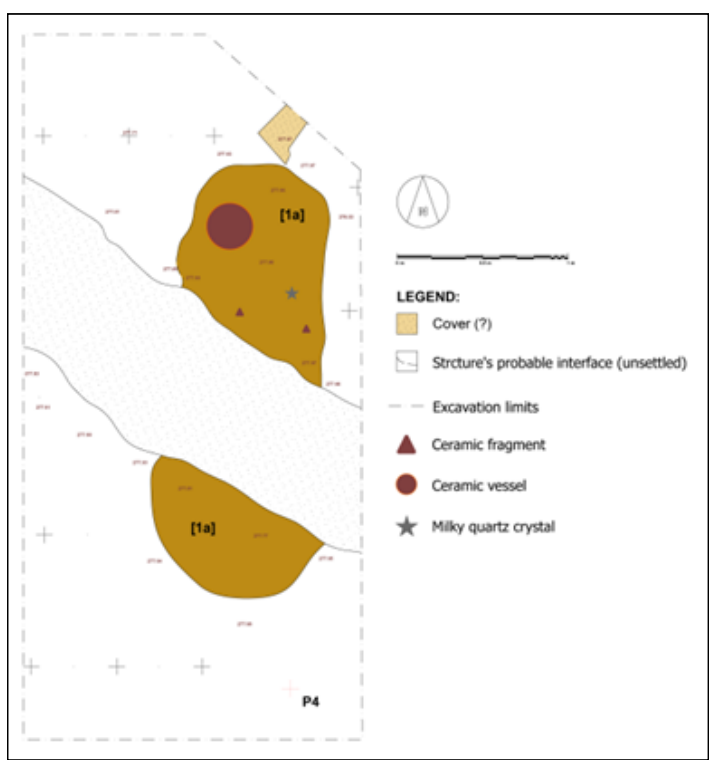

Fig. 6. Plano inicial da estrutura 12 onde é visível o corte transversal provocado pela abertura de uma vala.

Fig. 6. Structure 12 initial plant where it is visible the transversal cut made by the trench opening.
A estrutura apresentava contorno subretangular com os cantos arredondados, seção em "U" e base aplanada. O seu maior eixo encontrava-se alinhado no sentido norte-sul, atingindo os $252 \mathrm{~cm}$ de comprimento. A largura variava entre 80 e $108 \mathrm{~cm}$ e a profundidade oscilava entre os 10 e os $19 \mathrm{~cm}$ (Tabela 1). No extremo norte da sua base foi registada uma pequena depressão circular com cerca de $22 \mathrm{~cm}$ de diâmetro e $35 \mathrm{~cm}$ de profundidade (Fig. 7). O seu enchimento único [UEla] detinha coloração castanha escura, composição limosa, textura homogénea e compacidade média, preenchendo igualmente a pequena depressão. A definição desta depressão, em plano, ficou a dever-se à menor compacidade da terra na zona do seu topo.

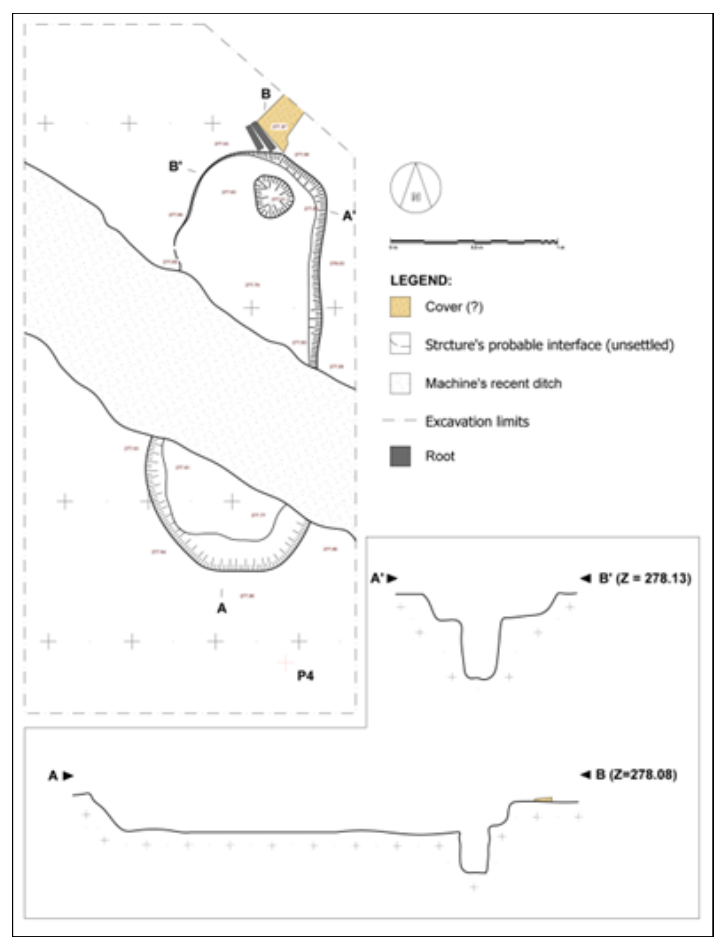

Fig. 7. Plano final e secções A-B e A'-B' da estrutura 12 após a sua escavação integral. Na extremidade norte pode observarse a pequena depressão circular escavada no subsolo.

Fig. 7. Structure 12 final plant and A-B and A'-B' sections after excavation. In its northern uttermost it can be seen a small circular depression open into the subsoil.

Tabela. 1. Contorno, seção, base e dimensões $(\mathrm{em} \mathrm{cm}$ ) da estrutura 12 Table. 1. Shape, section, base and dimensions (in $\mathrm{cm}$ ) of structure 12

\begin{tabular}{|c|c|c|c|c|c|}
\hline Contorno & Secção & Base & Comp. & Larg. & Prof. \\
\hline Subretangular & U & Aplanada & 252 & $80 / 108$ & $10 / 19$ \\
\hline
\end{tabular}

Imediatamente acima no extremo norte do interface desta estrutura, pela parte externa, foi identificado uma pequena língua de saibro compactado [UE1b]. Infelizmente, este vestígio havia sido largamente destruído pela ação mecânica da maquinaria a operar na zona. 
Do interior das terras que colmatavam esta estrutura, sensivelmente a $50 \mathrm{~cm}$ para sudeste da pequena depressão e junto da base, foi recolhida uma lasca de quartzo translúcido, com cerca de $1,5 \mathrm{~cm}$, e três pequenos fragmentos cerâmicos. Estes últimos revelam fabrico manual, pastas arenosas e cozeduras redutoras e não permitiram identificar as formas a que pertenceram. O seu reduzido tamanho (menor que $4 \mathrm{~cm}$ ), estado erodido dos cernes e dispersão por locais aleatórios da estrutura, embora denotando pastas semelhantes, favorecem a hipótese de terem sido acidentalmente transportados com as terras de enchimento.

No interior desta estrutura, na extremidade nornoroeste, foi depositado um vaso de largo bordo horizontal ${ }^{5}$ tecnicamente semelhante aos restantes fragmentos recolhidos (Fig. 8).

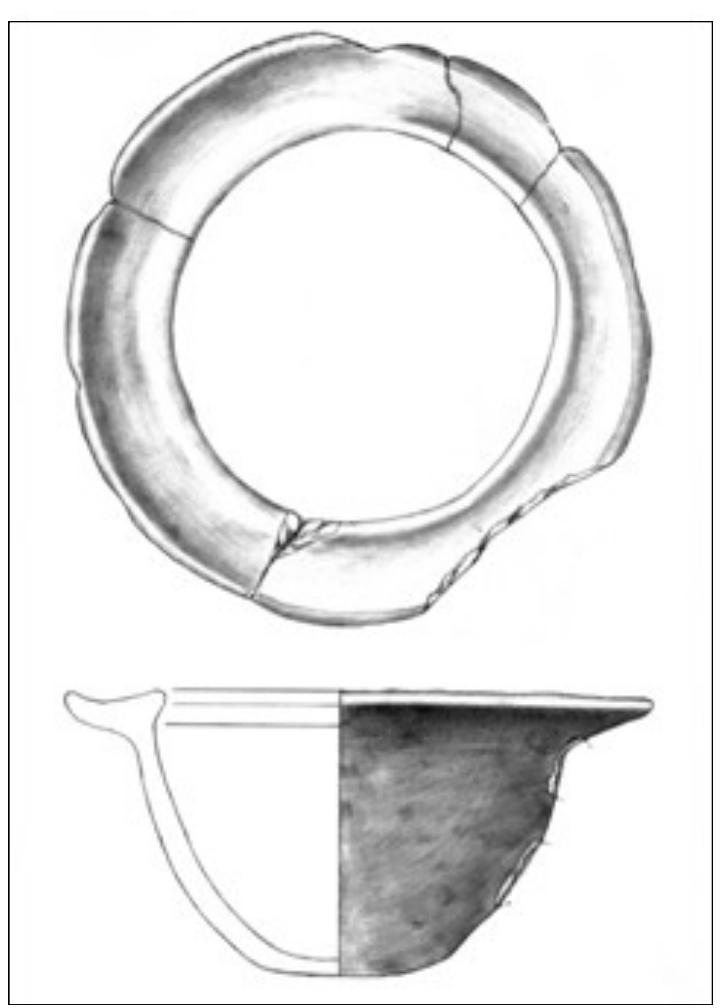

Fig. 8. Vaso cerâmico (2009.0765) recolhido do enchimento da estrutura 12.

Fig. 8. Ceramic vessel (2009.0765) recovered from structure 12 fillings.
Denota fabrico manual, pasta arenosa, textura grosseira, cozedura redutora de boa qualidade e acabamento polido na face externa e alisado na face interna. $O$ bordo varia entre 1,9 e $3,2 \mathrm{~cm}$ de largura, sendo o lábio arredondado. Mede cerca de 13,5 cm de diâmetro de boca. O fundo é maioritariamente convexo, com parte da superfície aplanada.

As fraturas presentes na parede externa mostram que o elemento de preensão vertical, em falta, seria de secção em fita. Nota-se, pela significativa antiguidade da patina da fratura, que a sua quebra detém significativa antiguidade, pelo que teria ocorrido antes da sua deposição. A falta de pequenas partes da aba poderão ser explicadas, talvez, pela textura grosseira da pasta e consequente menor resistência à acidez dos solos locais. $\mathrm{O}$ vaso apresentava fuligem em ambas as faces, sendo que na parede externa esta se distribuía pela zona oposta à asa. Contrariamente aos restantes fragmentos de exemplares ali recolhidos, este vaso não incluía qualquer decoração.

Encontrava-se depositado na vertical, embora abatido em três grandes partes, sendo que a asa estaria virada para o quadrante nascente.

\section{DATAÇÃO POR $\mathrm{C}^{14}$}

Para a datação deste contexto foi opção recolher uma amostra de fuligem raspadas da face interna do vaso depositado no interior da sepultura, visto que esta terá sido gerada num momento muito próximo da deposição do vaso no interior da estrutura.

$\mathrm{O}$ resultado obtido situa-se no segundo quartel do II milénio $\mathrm{AC}$, mais precisamente, entre os séculos XVII e XVI AC, tendo em conta a calibração a 2 sigma (Tabela 2 ).

Esta data é, aliás, consonante com o vaso recolhido, cuja presença neste tipo de contexto no Noroeste português tem vindo a inserir-se entre o Bronze Médio e o Bronze Final regionais (BETTENCOURT 1997, 1999, 2009, 2010a; CRUZ \& GONÇALVES 1998/1999).

Tabela. 2. Data calibrada com o programa OxCal 4.2., de acordo com a curva IntCa109 (REIMER et al. 2009) Table. 2. Calibrated date using $\mathrm{OxCal} 4.2$ program, according to IntCal09 curve (REIMER et al. 2009)

\begin{tabular}{|c|c|c|c|}
\hline Lab. Ref. & Date BP & Cal. 1 Sigma & Cal. 2 Sigma \\
& & $\mathbf{6 8 , 2} \%$ & $\mathbf{9 5 , 4 \%}$ \\
\hline AA89661 & $3345 \pm 42$ & $1689-1605(51.2 \%)$ & $1698-1524(86.8 \%)$ \\
& & $1576-1536(17 \%)$ & $1739-1705(8.6 \%)$ \\
\hline
\end{tabular}




\section{INTERPRETACÕES}

Tendo em conta as caraterísticas da estrutura escavada, isto é, a sua forma, as suas dimensões e a sua orientação, bem como a deposição, no seu interior, de um vaso cerâmico de largo bordo horizontal, parece viável afirmar que estamos perante uma sepultura plana. Em abono da função funerária destas estruturas registe-se o seu paralelo com as encontradas na necrópole do Pego, onde foi possível identificar a posição da inumação, em duas delas, pela estratigrafia (SAMPAIO \& BETTENCOURT 2014).

A forma e as dimensões desta sepultura apontam para a prática da inumação mas a ausência de ossos, recorrente pela acidez dos solos locais, não permite depreender se esta terá ocorrido em decúbito dorsal ou lateral, nem tão pouco identificar qual das extremidades corresponderia à cabeceira. As suas consideráveis dimensões, no que se relaciona com a largura, quando comparadas com estruturas semelhantes, não descartam a possibilidade de poder ter albergado uma inumação dupla.

Os indícios de fuligem presentes em ambas as faces do vaso depositado no interior daquela estrutura deixam depreender a queima de substâncias em momento anterior à sua deposição, situação compatível com outros vasos deste tipo presentes em contextos coetâneos no Noroeste da Ibéria (BETTENCOURT 2010). Nos vasos similares recolhidos na necrópole do Pego, em Braga, estas substâncias foram identificadas como sendo gordura (GONÇALVES et al. 2010).

A depressão circular identificada no quadrante Nordeste da base da sepultura, posicionado a cerca de $20 \mathrm{~cm}$ para nascente do local onde foi recolhido o vaso, é de difícil interpretação. Como hipótese de trabalho propõem-se a sua utilização enquanto "cama" ou contentor para albergar uma oferenda em material perecível. Tal poderia explicar a menor compacidade do enchimento verificada, durante os trabalhos de escavação, no topo desta pequena depressão.

A presença de um resquício de saibro compactado identificado na extremidade exterior norte do seu interface poderia corresponder ao resto da cobertura que teria selado esta sepultura. Situação similar foi identificada na necrópole do Pego (SAMPAIO \& BETTENCOURT 2014).

Os fragmentos dos outros três recipientes cerâmicos de largo bordo horizontal foram recolhidos na área imediata à suposta sepultura. Tal permite hipotetizar que estes poderiam estar originalmente depositados no interior de outras estruturas em negativo - sepulturas planas ou fossas -, entretanto destruídas pelos primeiros trabalhos do NHB Como mera hipótese de trabalho parece exequível assumir que na vertente su-sudoeste do monte de Pedroso foi construída uma necrópole cuja datação por radiocarbono a insere entre os séculos XVII/ XVI AC, ou seja, na Idade do Bronze Médio. Infelizmente, o projeto de construção do NHB não permitiu alargar a área de escavação para nordeste e este deste local, área para onde, presumivelmente, se poderia estender a suposta área de necrópole. Como consequência direta ficam algumas questões em aberto, nomeadamente, a sua dimensão, as caraterísticas da sua organização interna e a sua diacronia de utilização.

Necrópoles de sepulturas planas da Idade do Bronze são comuns no Noroeste de Portugal, em áreas de baixa altitude e/ou vinculadas a vales agrícolas, conforme está bem sintetizado em Bettencourt (2010). Na própria bacia do rio Este é conhecida a do Pego, radiometricamente datada do Bronze Médio (SAMPAio et al. 2008; SAMPAIO \& BetTENCOURT 2013). Noutras áreas do Noroeste português conhecem-se também as da Tapada da Caldeira, em Baião (JORGE 1980a, 1980b, 1983, 1985) igualmente datada por $\mathrm{C}^{14}$ do Bronze Médio -, de Cimalha, em Felgueiras (ALMEIDA \& FERNANDES 2007, 2008; ALMEIDA et al. 2008; BETTENCOURT 2009) e a do Alto da Vela, em Gulpilhares (FORTES 1909). Na vizinha Galiza, em Espanha, conhecem-se as necrópoles de sepulturas planas de Coto da Laborada, em Calvos de Randín (LóPEZ Cuevillas 1930, 1947; López Cuevillas \& LORENZO FERnÁndeZ 1930) e de Monte de Mesiego, em O Carballiño (LÓPEZ CUEvILlas \& CHAMOSO LAMAS 1958).

Além disso, são igualmente conhecidas no Noroeste português vários contextos funerários onde foram identificados vasos de bordo horizontal. Referimo-nos, concretamente, às necrópoles de Belinho (ALMEIDA 1986; BETTENCOURT 1999) e de Agra de Antas (AtAíde \& TeIXEIRA 1940), ambas em Esposende, do Monte da Ola (PAÇO 1933), em Viana do Castelo, de Faísca, em Guimarães (CARDOSO 1936), de Cimalha, em Felgueiras (ALMEIDA \& FERNANDES 2007, 2008; ALMEIDA et al. 2008) e de Alto da Vela/Gulpilhares (FORTES 1909), em Vila Nova de Gaia. Na vizinha Galiza, um interessante exemplar foi recolhido na necrópole de Coto da Laborada, em Calvos de Randín (LÓPEZ CuEviLlas \& LOURENZO FERNÁNDEZ 1930). Esta forma surge, igualmente, em reutilizações de monumentos, como são exemplo os monumentos de Lordelo de Cima/Chafé, em Viana do Castelo (SiLva \& MARques 1986) e de Monte da Romea, em Lalín (PRIETO MARTíNEZ 2007).

A escassez de dados relativos à prática de cremação durante a Idade do Bronze, para o Noroeste português, não permite grandes ilações sobre a coexistência desta prática com a de inumação. Infelizmente, apenas se conhece o sítio de Agro da Nogueira, um local onde, segundo as autoras, terá ocorrido a utilização de uma estrutura cistóide para a deposição de uma cremação, cuja datação remontará ao Calcolítico Final ou ao Bronze Inicial (BETTENCOURT \& MeiJide CAMESElle 2009). 
Observando o local escolhido para a construção desta eventual necrópole, verifica-se que foi eleita a vertente sul do monte de Pedroso, área bem exposta ao sol e bem iluminada ao longo de todo o dia. Conforme o defendido para a necrópole do Pego (SAmpaio \& Bettencourt 2014), onde situação semelhante se confirma, questionamo-nos se a escolha do local relacionará simbolicamente o ciclo solar com o ciclo da vida e da morte. Também a sua localização numa vertente parece ser significante, pois as vertentes são espaços de transição entre o vale e o topo do monte, ou seja, lugares liminares e de passagem entre diferentes espaços naturalmente significantes. Tal permite-nos questionar, igualmente, se esta característica física, associada à morte, não pode ser uma metáfora da passagem entre dois mundos: o da vida e o da morte.

É certo que algumas das propostas apresentadas carecem, obviamente, de validação através de mais exemplos. Tal só poderá ser conseguido com mais trabalhos de escavação, conjugando os novos dados com os resultados já disponíveis. Mas não é menos verdade que este processo é um trabalho moroso, em alguns caso, nem sempre facilitado pelas condições de registo, do qual o presente trabalho é um bom exemplo. Ainda assim, é um trilho indispensável à contínua construção do conhecimento sobre as comunidades da Idade do Bronze do Noroeste português, em concreto, sobre o seu universo funerário.

\section{AGRADECIMENTOS}

O presente trabalho foi desenvolvido no âmbito dos projetos Lugares da Idade do Bronze na bacia do Ave LIBVA [PNTA2008/1(554), financiado pela FCT (SFRH/ $\mathrm{BD} / 41776 / 2007)]$ e Espaços naturais, arquitecturas, arte rupestre e deposições na pré-história recente da fachada ocidental do centro-norte português: das acções aos significados - ENARDAS (PTDC/HIS-ARQ/112983/2009), financiado pelo Programa Operacional Temático Factores de Competividade - COMPETE e comparticipado pelo Fundo Comunitário Europeu - FEDER. Agradece-se, ainda, à equipa técnica e do Museu Regional de Arqueologia D. Diogo de Sousa, em Braga, em especial à Clara Lobo, ao Manuel Santos e à Amélia Marques, e a Filipe Pereira e a Hélia Aluai Sampaio, respetivamente, responsáveis pela conceção dos mapas e dos desenhos apresentados.

\section{BIBLIOGRAFIA}

ALMEIDA, C.A.B. 1986. Carta arqueológica do concelho de Esposende. Boletim Cultural de Esposende, 9/10: 39-59.

AlmeidA, C.A.B.; AlmeidA, P.B. \& Fernandes, F. 2008. Povoado do Bronze Final da Cimalha: relatório da interpretação arqueológica. Felgueiras: Câmara Municipal.

Almeida, P.B. \& Fernandes, F. 2008. O povoado da Idade do Bronze da Cimalha. Actas do I Encontro de Arqueologia das Terras do Sousa (Lousada, 2007). [Oppidum, Número Especial]: 29-44.

AlmeIDA, P.B. \& FernANDES, F. 2007. A escavação arqueológica no povoado das Cimalhas - Felgueiras. Oppidum, 2: 115-123.
ATAíDE, A. \& TEIXEIRA, C. 1940. A necrópole e o esqueleto de S. Paio de Antas e o problema dos vasos de largo borde horizontal. Actas do $1^{\circ}$ Congresso do Mundo Português (Lisboa, 1940). Lisboa, 669. 692.

BArbosA, R. \& AzEvedo, M. 2004-2005. A antropização da paisagem no vale do Este: dados inéditos para o seu estudo. Minia, 11-12 ( $3^{\text {a }}$ Série): 113-136.

BARRETT, J.C. 1994. Fragments from Antiquity. Oxford: Blackwell.

Bettencourt, A.M.S. 1997. Expressões funerárias da Idade do Bronze no Noroeste peninsular. Actas do II ${ }^{\circ}$ Congreso de Arqueología Peninsular (Zamora 1996). Zamora: Fundación Rei Afonso Henriques, 621-632.

Bettencourt, A.M.S. 1999. A Paisagem e o Homem na bacia do Cávado durante o II e o I milénios AC (5 Vols.). Braga: Universidade do Minho (Tese de Doutoramento - policopiada).

Bettencourt, A.M.S. 2009. A Pré-História do Minho: do Neolítico à Idade do Bronze. In P. Pereira (coord.). Minho. Traços de Identidade, Braga: Universidade do Minho, 70-113.

Bettencourt, A.M.S. 2010. La Edad del Bronce en el Noroeste de la Península Ibérica: un análisis a partir de las prácticas funerárias. Trabajos de Prehistoria, 67 (1): 139-173.

Bettencourt, A.M.S. \& Meijide Cameselle, G. 2009. Agro de Nogueira, Melide, A Coruña: novos dados e novas problemáticas. Gallaecia, 28: 33-40.

CARDoso, M. 1936. Novas urnas de largo bordo horizontal (um tipo regional de cerâmica primitiva). Trabalhos de Antropologia e Etnologia, 8 (1): 65-87.

Cruz, D.J. \& GonÇAlves, A.A.H.B. 1998-1999. A necrópole de "Agra de Antas" (S. Paio de Antas, Esposende, Braga). Portugalia 19-20 (Nova série). Porto: 5-27.

FÁBregas VALCARCE, R. 2001. Los petroglifos y su contexto: un ejemplo de la Galicia meridional. Vigo: Instituto de Estudios Vigueses.

FELD, S. \& BASSO, K.H. 1996. Senses of Place. Santa Fe, New Mexico: School of American Research Press.

Ferreira, N.; Dias, G.; Meireles, C.; Braga, A.; FranCISCO, S. \& SANTOS, A. 2000. Carta Geológica de Portugal na escala 1:50 0000. Notícia explicativa da folha 5D (Braga). Lisboa: Instituto Geológico e Mineiro \& Universidade do Minho.

FORTES, J. 1909. Gaya no passado. Mea villa de Gaya. Porto: Empresa Editorial do Guia Ilustrado de Portugal.

Gonçalves, L.; Bettencourt, A.M.S. \& Alves, M.I.C. 2010. Análises químicas de conteúdos orgânicos de recipientes cerâmicos da Idade do Bronze do Norte de Portugal. III Jornadas do Quaternário Evolução Paleoambiental e Povoamento na Fachada Ocidental da Península Ibérica (Braga 2010). Braga: APEQ, 8.

JoRgE, S.O. 1980a. A necrópole do Tapado da CaldeiraBaião. Arqueologia, 2: 36-44.

JORGE, S.O. 1980b. A estação arqueológica do Tapado da Caldeira, Baião. Portugalia, 1 (Nova série): 29-50. 
JORGE, S.O. 1983. Duas datas de C14 para a sepultura 1 da estação do Tapado da Caldeira (Baião). Arqueologia, 8: 55-56.

JoRge, S.O. 1985. Datas de Carbono 14 para a Pré-História Recente do Norte de Portugal: os dados e os problemas. Arqueologia, 12: 154-183.

LÓPEZ Cuevillas, F. 1930. Nuevas cerámicas das antas galegas. Trabalhos da Sociedade Portuguesa de Antropologia e Etnologia, 4: 263-282.

LóPez Cuevillas, F. 1947. Los vasos semiovoides y la cronología de los vasos de ancho borde horizontal. Boletin de la Comisión Provincial de Monumentos Históricos y Artísticos de Orense, 16 (1): 1-12.

LÓPEZ Cuevillas, F. \& Chamoso Lamas, M. 1958. Una necrópolis de sepulturas planas. Cuadernos de Estudios Gallegos, 13 (39): 273-283.

LÓPEZ Cuevillas, F. \& LORENZO FERnÁNDEZ, X. 1930. Vila de Calvos de Randin. Notas Etnográficas e Folklóricas. Santiago de Compostela: Seminario de Estudios Galegos.

PAÇO, A. 1933. Vaso de bordo horizontal, de Vila Fria. Homenagem a Martins Sarmento. Guimarães: Sociedade Martins Sarmento, 272-276.

PRIETO MARTíneZ, M.P. 2007. Volviendo a un mismo lugar: recipientes y espacios en un monumento megalítico galego (NW de España). Revista Portuguesa de Arqueologia, 10 (2): 101-125

ReIMER, P.J.; BAIllie, M.G.L.; BARD, E.; BAYLISS, A.; BECK, J.W.; BlaCKWEll, P.G.; RAMSEY, C.B.; BUCK, C.E.; BURR, G.S.; EDWARDS, R.L.; FrIEDRICH, M.; GROOTES, P.M.; GUILDERSON, T.P.; HAJDAS, I.; HEATON, T.J.; HogG, A.G.; Hughen, K.A.; KAISER, K.F.; Kromer, B.; MCCORMAC, F.G.; MANNING, S.W.; REIMER, R.W.; RICHARDS, D.A.; SOUTHON, J.R.; TALAMO, S.; TURNEY, C.S.M.; VAN DER PliCht, J. \& WEYHENMEYER, C.E. 2009. IntCal13 and Marine13 Radiocarbon Age Calibration Curves 0-50,000 Years Cal BP. Radiocarbon, 55 (4): 1869-1887.
SAmpaio, H.A.; Bettencourt, A.M.S.; Barbosa, R. Dinis, A. \& CRUZ, D. 2008. A importância do povoado do Pego no Bronze do Noroeste de Portugal. In E. Ramil Rego (Ed.) Actas do 1 Congreso Internacional de Arqueoloxía de Vilalba [Férvedes 5], 227-233.

SAmpaio, H.A. \& Bettencourt, A.M.S. 2014. Between valleys and the hill top. Discoursing on the spatial importance of Pego's Bronze Age necropolis , Braga, (Northwest of Portugal). Estudos do Quaternário, 10: 45-57.

Silva, E.J. \& MARQUES, J.A.M. 1984. Escavação de uma cista em Lordelo (Anha - Viana do Castelo). Revista de História, 1: 51-72.

TeiXeira, C.; Medeiros, A.; Assunç̃̃o, C. \& Torre, C.F. 1965. Carta Geológica de Portugal na escala 1:50 000. Notícia explicativa da folha 9-A (Póvoa de Varzim). Lisboa: Serviços Geológicos de Portugal.

Teixeira, C. \& Medeiros, A. 1969. Carta Geológica de Portugal na escala 1:50 0000. Notícia explicativa da folha 5C (Barcelos). Lisboa: Serviços Geológicos de Portugal.

THOMAS, J. 2001. Archaeologies of place and landscape. In I. Hodder (Ed.) Archaeological Theory Today. Cambridge: Polity Press, 165-186.

VAN DyKe, R.M. \& ALCOCK, S. 2003. Archaeologies of Memory: an introduction. In R.M. Van Dyke \& S.E. Alcock (eds.) Archaeologies of Memory. Oxford: Blackwell, 1-13.

WhittLe, A. 2010. The diversity and duration of memory. In D. Boric (Ed.) Archaeology and Memory, Oxford: Oxbow Books, 35-47. 